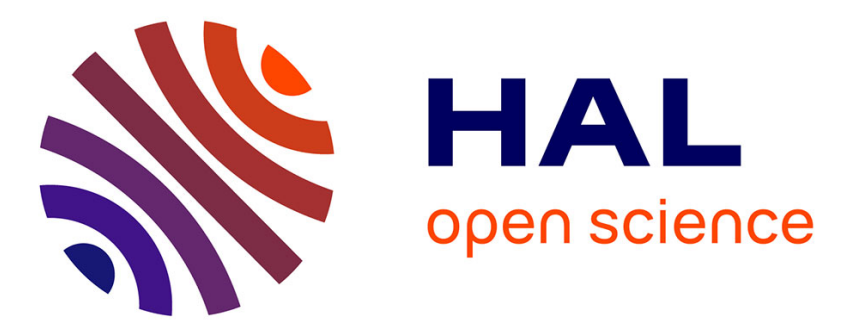

\title{
Application and evaluation of LS-PIV technique for the monitoring of river surface velocities in high flow conditions
}

\author{
M. Jodeau, A. Hauet, André Paquier, J. Le Coz, Guillaume Dramais
}

\section{- To cite this version:}

M. Jodeau, A. Hauet, André Paquier, J. Le Coz, Guillaume Dramais. Application and evaluation of LS-PIV technique for the monitoring of river surface velocities in high flow conditions. Flow Measurement and Instrumentation, 2008, 19 (2), p. 117 - p. 127. 10.1016/j.flowmeasinst.2007.11.004 . hal-01016952

\section{HAL Id: hal-01016952 https://hal.science/hal-01016952}

Submitted on 1 Jul 2014

HAL is a multi-disciplinary open access archive for the deposit and dissemination of scientific research documents, whether they are published or not. The documents may come from teaching and research institutions in France or abroad, or from public or private research centers.
L'archive ouverte pluridisciplinaire HAL, est destinée au dépôt et à la diffusion de documents scientifiques de niveau recherche, publiés ou non, émanant des établissements d'enseignement et de recherche français ou étrangers, des laboratoires publics ou privés. 


\section{Application and evaluation of LS-PIV technique for the monitoring of river surface velocities in high flow condi- tions}

abbreviated title: LS-PIV measurements in high flow conditions

M. Jodeau ${ }^{1}$, A. Hauet ${ }^{2}$, A. Paquier ${ }^{1}$, J. Le Coz ${ }^{1}$, G. Dramais ${ }^{1}$

1. Cemagref, 3 bis quai Chauveau CP 220 F-69336 Lyon Cedex 09 France

2. LTHE, UMR5564, BP53, 38041 Grenoble France

Correspondence to Magali Jodeau

E-mail : jodeau@lyon.cemagref.fr ; Tel. +33472 208786 ; Fax +3347847 7875

\section{Abstract}

Large Scale Particle Image Velocimetry (LS-PIV) is used to measure the surface flow velocities in a mountain stream during high flow conditions due to a reservoir release. A complete installation including video acquisition from a mobile elevated view-point and artificial flow seeding has been developed and implemented. The LS-PIV method was adapted in order to take into account the specific constraints of these high flow conditions. Using a usual LS-PIV data processing, significant variations of the water surface elevation were taken into consideration in the image rectification. An intensity threshold was applied to focus on artificial tracers without considering stationary waves and sun reflections on the flow surface. A site-specific float coefficient of 0.79 based on measured vertical velocity profiles was used to convert surface velocities into depth-averaged velocities. Comparison between LS-PIV assessments and 2Dh numerical calculations with the code Rubar20 allows verification and extrapolation of LS-PIV data. LS-PIV velocity measurements permit to assess discharges 
over the whole high flow event in agreement with leaded current-meter measurements performed at a downstream bridge.

Keywords: LS-PIV; river discharge measurement; flow velocity; high flow condition; 2Dh numerical calculation

\section{Introduction}

The investigation of flow velocities is essential in the study of sediment deposition and erosion patterns in rivers, see for instance [1, 2, 3]. Especially, the knowledge of flow conditions associated with floods is required for the study of river bed morphology, as high flows mainly contribute to morphological changes (for field example, see [4]).

In mountain streams, velocity measurements and discharge estimates are usually based on leaded current-meter measurements from bridges or wires set across the river width. Usual velocity measurements in rivers using leaded current-meter provide data with poor spatial and temporal resolutions. For instance, one hour is needed to measure velocities over a $50 \mathrm{~m}$ cross-section and measurements are often limited to one cross-section in the vicinity of a bridge. Other measurement solutions like Doppler profilers (aDcp) involve intrusion in the river (boat or floating board) which is not always easy and safe [5]. During high flow conditions, high flow velocities, large water depths and large floating objects (trunk, debris) prevented any kind of systematic intrusive flow measurements. Non-intrusive velocity measurements are needed when natural conditions do not permit the use of conventional techniques. Chemical dilution methods can provide precise discharge estimates but they do not give information on the velocity field structure. 
Partly due to the improvement of computing capabilities, digital imaging techniques are increasingly being used in environmental field measurements. In the present study, LS-PIV (Large Scale Particle Image Velocimetry) is used to measure velocity fields at the flow surface without intrusion in the flow at the river scale. LS-PIV is an image based method which consists in recording images of the flow surface and calculating the most likely displacements of patterns using statistical identification [6].

This velocity measurement technique is used in laboratory experiments [7, 8, 9], as well as in natural conditions [10]. Unlike PIV used in laboratory with laser illumination that allows the exploration of the whole flow, LS-PIV with natural light is restricted to surface flow investigation. LS-PIV method has been used in high flow conditions to measure flow velocities [6], and up to now, this technique has been used in rivers for many applications: river discharge calculation [11, 12], aquatic habitat mapping studies [13], assessment of mean flow patterns between groins [14]...

Natural floods often carry many objects or turbulence-driven patterns (ripples, boils) which are more or less visible at the surface of the flow. If dense enough, they can be used as traceable patterns in the LS-PIV procedure, for instance floating ice can be considered [15]. Artificial seeding is required when few natural tracers are visible at the surface of the flow $[16,8,17,9]$

In this paper, LS-PIV is applied in field conditions during a reservoir release. These velocity measurements are part of an extensive investigation of the morphological changes over a gravel alternate bar [18].

In order to estimate flow velocities over the bar during the high flow event, a complete installation was elaborated to record large images of the flow which can be analyzed using 
LS-PIV method according to [19, 12]. The installation includes (i) a remotely controlled mobile image recording system from an elevated point and (ii) an artificial flow seeding system as no natural tracers were visible at the surface of the flow. To authors' knowledge this kind of installation has not been used in rivers before. The LS-PIV method was improved to consider the specific constraints of these high flow conditions: significant variations of the water surface elevation, dark water color due to very high fine sediment loads, tree shadows and sun reflections on the flow surface. Evaluation of LS-PIV technique adapted to high flow condition and mountain stream is performed owing to comparisons with 2Dh numerical calculations. Flow discharge is computed from LS-PIV measurements throughout the whole event. Direct comparison is made with two leaded current-meter measurements and with the discharge calculated by river managers from hydraulic structure laws.

The first part of this paper presents the measurement installation. The second part describes the LS-PIV method. The third part details flow velocity patterns and comparison between experimental results and 2Dh numerical calculations. The fourth part deals with discharge calculation and comparison with discharge estimates from leaded current-meter measurements.

\section{Measurement installation}

\subsection{Mast and video camera}

A commercially available digital video camera (Canon MV 750i) was used to record the river flow. Sequences format was mini-DV at a rate of 25 frames per second and image resolution was $540 \times 720$ pixels. The video camera was set on a mobile lightweight telescopic mast which height can be set from 2 to $10 \mathrm{~m}$ (Maxi Primo, Fireco Components). Four shrouds were hold 

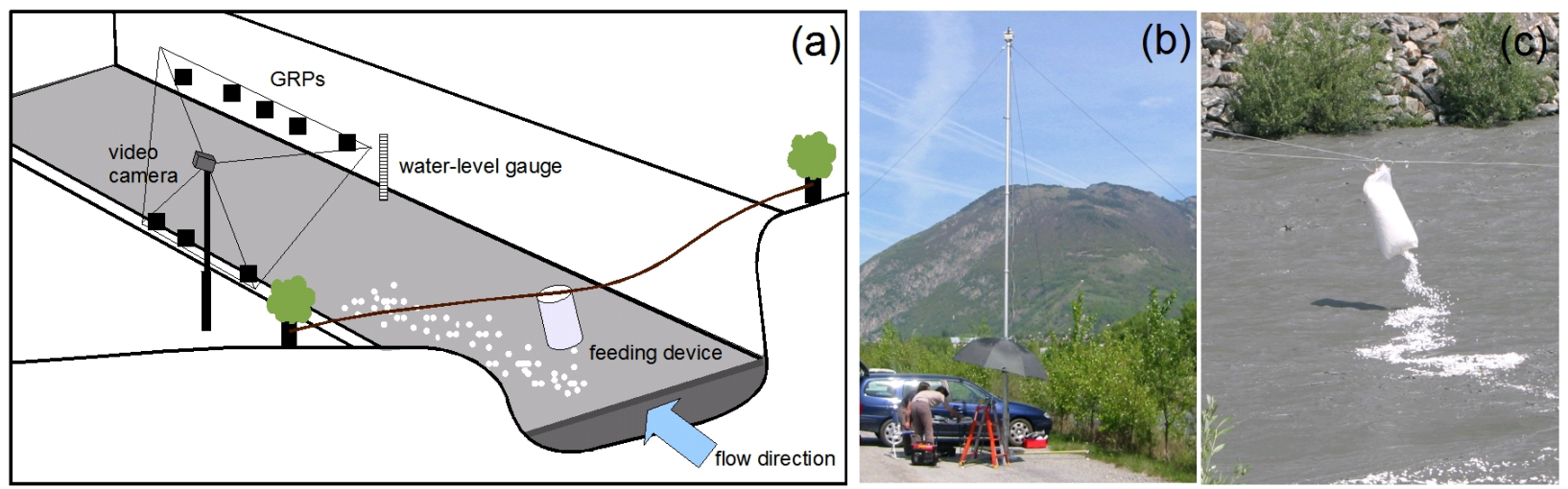

Figure 1: (a) Schematic view of the LS-PIV installation: mast, video-camera and view field, Ground

Reference Points (GRPs), tracer feeding device and water level gauge. (b) Picture of the mobile lightweight telescopic mast, the river is in the foreground behind the trees. (c) Picture of the feeding device in action.

from the top of the mast to the ground to reduce wind disturbance (Figure $1 \mathrm{~b}$ ). The camera was remotely controlled from the ground to set the camera on and to adjust view angles. The movies were directly saved on a laptop. Several Ground Reference Points (GRPs) were positioned in the view field at the same elevation using squares painted on embankments and white square targets to allow further geometric correction of the pictures.

\subsection{Artificial tracer feeding device}

As the surface flow did not show clearly visible patterns, a simple feeding device was developed to supply the flow with Ecofoam chips, a water soluble, foamed filling material created from cornstarch. It is biologically degradable, and as supplied quantities are insignificant in regards to the water flux, it does not affect the water quality of the river. As high flow conditions prevent any sailing or wading in the river, a $50 \mathrm{~m}$-long rope was set up between 
both banks $50 \mathrm{~m}$ upstream from the camera view-point. A sliding container made of a plastic bag disseminated white chips over the flow (Figure 1). The installation is quite similar to a tyrolean traverse. The disseminator movement was controlled from both banks by operators pulling a rope fastened to the chip container. At first, the tracers float on the surface, then they dissolve in water within less than one minute.

During the 1 day-long dam flushing operation, eight sequences of chip fed flows (and 17 sequences without artificial tracers) were recorded over a wide range of discharges and analyzed using LS-PIV method.

The LS-PIV analysis was conducted on around 200 to 1500 image pairs per sequence, with a $0.2 \mathrm{~s}$ interval time between images.

\section{Improved LS-PIV technique}

\subsection{Geometric rectification: GRP and variations of water surface elevation}

The first step in the LS-PIV procedure consists in geometrically correcting images to obtain ortho-images (Figure 2). This is usually realized by considering the water surface as a plan of constant elevation, which leads to an 8-parameters plan-to-plan perspective projection that can be solved using at least 4 GRPs located at the river free-surface elevation (see [20] for instance). In this study, the water level varied for more than one meter during the dam release. We placed the GRPs in a horizontal plan parallel to the river surface which elevation was higher than the expected maximum water level during the flushing event. The conventional projection equations corrected to take into account the water level changes are 
Author-produced version of the article published Flow Measurement and Instrumentation (2008), 19, 2, 117-127,

The original publication is available at http://www.sciencedirect.com DOI: 10.1016/j.flowmeasinst.2007.11.004

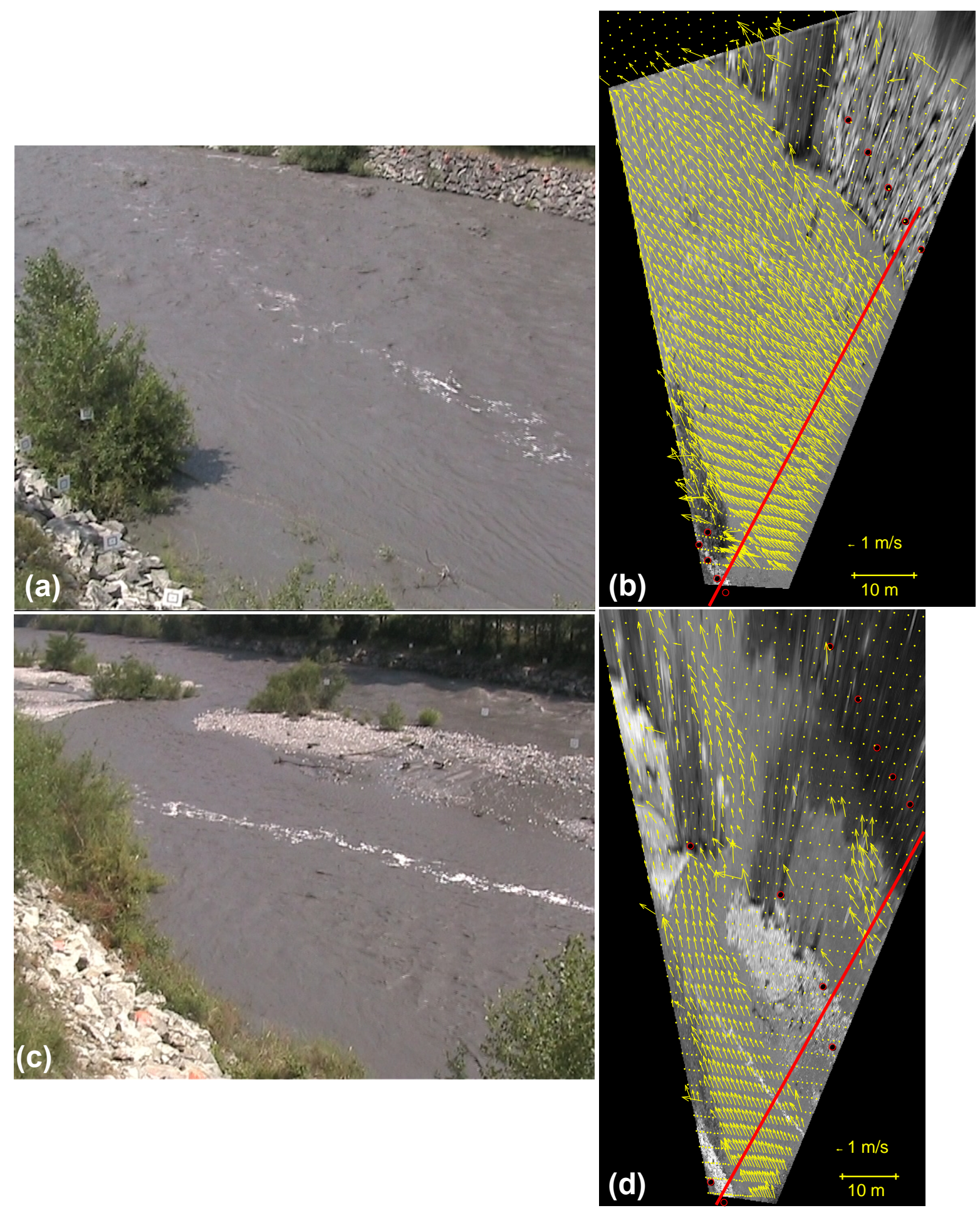

Figure 2: Typical flow images before and after rectification, LS-PIV time-averaged surface velocity fields and cross-section used for transect analysis: Site D (a) and after rectification (b), Site C (c) and after rectification $(\mathrm{d})$. 
expressed as:

$$
\begin{aligned}
& i=\frac{a_{1} x+a_{2} y+a_{3} z+a_{4}}{c_{1} x+c_{2} y+c_{3} z+1} \\
& j=\frac{b_{1} x+b_{2} y+b_{3} z+b_{4}}{c_{1} x+c_{2} y+c_{3} z+1}
\end{aligned}
$$

where $[i, j]$ are the coordinates in the image coordinate system (in pixel) of the point of Cartesian coordinates $[x, y, z]$. As the river surface can be considered planar, the coordinate $z$ can be expressed as:

$$
z=d_{1} x+d_{2} y+d_{3}
$$

Using the assumption that the river surface slope is small at the considered scale of study, we reduce the previous equation to $z=d_{3}(t)$. Combining the expression of $z$ in Equation (1) leads to:

$$
\begin{aligned}
i & =\frac{a_{1} x+a_{2} y+a_{3} d_{3}(t)+a_{4}}{c_{1} x+c_{2} y+c_{3} d_{3}(t)+1} \\
j & =\frac{b_{1} x+b_{2} y+b_{3} d_{3}(t)+b_{4}}{c_{1} x+c_{2} y+c_{3} d_{3}(t)+1}
\end{aligned}
$$

where $d_{3}(t)$ is simply the difference of level between the plan of the GRPs and the water level given by the limnigraphs at time $t$. The system of Equation (4) and (5) has 11 unknowns, so it can be solved using at least $\mathrm{N} \geq 6$ GRPs giving 13 coordinates: $z_{G R P}$ and $\left(x_{i}, y_{i}\right)$ where $\mathrm{i}=1$ to 6 as: 
$\mathcal{E} \mathcal{F}=\mathcal{G}$ where

$$
\begin{aligned}
& \mathcal{E}=[11 \times 2 N]=\left[\begin{array}{ccccccccccc}
x_{1} & y_{1} & d_{3} & 1 & 0 & 0 & 0 & 0 & -i_{1} x_{1} & -i_{1} y_{1} & -i_{1} d_{3} \\
x_{2} & y_{2} & d_{3} & 1 & 0 & 0 & 0 & 0 & -i_{2} x_{2} & -i_{2} y_{2} & -i_{2} d_{3} \\
\vdots & \vdots & \vdots & \vdots & \vdots & \vdots & \vdots & \vdots & & & \\
x_{N} & y_{N} & d_{3} & 1 & 0 & 0 & 0 & 0 & -i_{N} x_{N} & -i_{N} y_{N} & -i_{N} d_{3} \\
0 & 0 & 0 & 0 & x_{1} & y_{1} & d_{3} & 1 & -j_{1} x_{1} & -j_{1} y_{1} & -j_{1} d_{3} \\
0 & 0 & 0 & 0 & x_{2} & y_{2} & d_{3} & 1 & -j_{2} x_{2} & -j_{2} y_{2} & -j_{2} d_{3} \\
\vdots & \vdots & \vdots & \vdots & \vdots & \vdots & \vdots & \vdots & & & \\
0 & 0 & 0 & 0 & x_{N} & y_{N} & d_{3} & 1 & -j_{N} x_{N} & -j_{N} y_{N} & -j_{N} d_{3}
\end{array}\right] \\
& \mathcal{F}=[11 \times 1]=\left[a_{1}, a_{2}, a_{3}, a_{4}, b_{1}, b_{2}, b_{3}, b_{4}, c_{1}, c_{2}, c_{3}\right]^{T} \\
& \mathcal{G}=[2 N \times 1]=\left[i_{1}, i_{2}, \ldots, i_{N}, j_{1}, j_{2}, \ldots, j_{N}\right]^{T}
\end{aligned}
$$

The equation is solved using a least-square method:

$$
\mathcal{F}=\left(\mathcal{E}^{T} \mathcal{E}\right)^{-1} \mathcal{E}^{T} \mathcal{G}
$$

The inverse relation mapping image coordinates onto Cartesian coordinates is:

$$
\begin{aligned}
x & =\frac{m_{1} i+m_{2} j+m_{3}}{p_{1} i+p_{2} j+p_{3}} \\
y & =\frac{q_{1} i+q_{2} j+q_{3}}{p_{1} i+p_{2} j+p_{3}}
\end{aligned}
$$

where the $m_{i}, p_{i}$ and $q_{i}$ parameters can be found in Annex 1.

\subsection{LS-PIV data processing}

A classical cross-correlation algorithm was used to determine the displacement of the flow tracers. In this study, we use a PIV algorithm for large scale applications with low resolution 
images, developed by [21]. It calculates the correlation between the interrogation area (IA) centered on a point $a_{i j}$ in the first image (image A) and the IA centered at point $b_{i j}$ in the second image (image B) recorded with a time interval of $\delta$ t seconds. The correlation coefficient $R\left(a_{i j}, b_{i j}\right)$ is a similarity index for the gray-scale intensity of a group of pixels contained in the two compared IAs, expressed as:

$$
R\left(a_{i j}, b_{i j}\right)=\frac{\sum_{\substack{1 \leq i \leq M i \\ 1 \leq j \leq M j}}\left(A_{i j}-\overline{A_{i j}}\right)\left(B_{i j}-\overline{B_{i j}}\right)}{\left[\sum_{\substack{1 \leq i \leq M i \\ 1 \leq j \leq M j}}\left(A_{i j}-\overline{A_{i j}}\right)^{2} \sum_{\substack{1 \leq i \leq M i \\ 1 \leq j \leq M j}}\left(B_{i j}-\overline{B_{i j}}\right)^{2}\right]^{1 / 2}}
$$

where $M i$ and $M j$ are the sizes of the interrogation areas (in pixels), and $A_{i j}$ and $B_{i j}$ are the distributions of the gray-level intensities in the two interrogation areas. Correlation coefficients are only computed for points $b_{i j}$ within some search area (SA).

The PIV approach assumes that the most probable displacement of the fluid from point $a_{i j}$ during period $\delta \mathrm{t}$ is the one corresponding to the maximum correlation coefficient. Sub-pixel displacement accuracy can be reached using a parabolic fit [22]. Velocity vectors are derived from these displacements by dividing them by $\delta$. The process is iteratively conducted for the whole image. The interrogation area was set as covering a physical surface of $2 \times 2 \mathrm{~m}^{2}$, which is small enough to preserve the scale of interest in the flow since any flow scales smaller than the size of the interrogation area are lost through processing, and large enough to include recognizable tracer patterns within it, i.e. to encompass one or more typical chips patterns that are used to trace the flow free surface.

LS-PIV analysis gave the instantaneous and time-averaged 2D surface velocity fields. Due to some temporary lacks of clearly visible patterns in some limited areas of the view field, it happens that instantaneous surface velocity is not estimated in such areas, they are com- 
puted as zero surface velocity. In order not to underestimate time-averaged velocity, for each calculation node the average is performed only with times leading to non-zero velocity. In many PIV studies several criteria, global or local filtering processes, are used to reduce the number of bad vectors $[8,23,24]$. In the present work LS-PIV performances are evaluated without implementing any systematic criteria on calculated velocities.

\subsection{Intensity threshold: tracers and stationary waves}

The flow regime during the high discharge period was highly turbulent, locally creating hydraulic jumps and stationary waves. In many LS-PIV post-processing methods all the visible patterns are taken into account $[10,20]$. The specular reflection of the sun on those waves created bright quasi-fixed patterns, but not immobile like trees for instance. A threshold on gray-scale images was used to focus on chip patterns (that appear completely white on the images) and to avoid taking into account light reflection on stationary waves (that appear darker). The threshold value is related to the image global illumination level.

Some attempts to analyze images without tracers led to a significant underestimation of surface flow velocities. Indeed comparison at the same calculation node between velocity estimates using a threshold (v1) and velocity estimates using classical calculation (v2) (Figure 3) shows that v1 is higher than v2 in most of the cases. Points at $0 \mathrm{~m} / \mathrm{s}$ correspond to velocities detected only by one of both analyses. Surface velocities are underestimated by $0.7 \mathrm{~m} / \mathrm{s}$ on average for a majority of sequences (D1, D3 to D6). Unfortunately, no obvious relationship can be established between analyses without a threshold and analyses with a threshold. Thus in the following, only the results obtained from thresholded images were used. 
The work of [24] suggests that a seeding-density 10-30\% of the surface may be enough to avoid major error in the estimation of surface velocities. In this field application, as tracer patterns were restricted to artificial seeding, tracer density is less than $10 \%$ of the river flow surface. It leads to large areas without calculated velocities, but this effect is corrected using a time-average processing (3.2) adapted to low tracer density.

Artificial seeding permits to add tracers in the far field. Without artificial tracers, velocity vectors were only obtained in the near field region because no image patterns were captured in the far-field. This effect of the decreasing of resolution over the image was highlighted by [25]. In the present field study, the white color of tracers is essential because it maximizes the contrast with the black color of the river. However, in shadow areas, contrast between water and tracers is poorer than in the rest of the image leading to flow areas without velocity assessment.

\section{Evaluation of LS-PIV surface velocity measurements}

The installation and method described above were evaluated on two different flow configurations in a mountain stream during a reservoir release.

\subsection{Site description and flushing operation}

The field work took place on the River Arc, France, during a reservoir release (June, 27 2006). Once a year this gravel bed river undergoes a reservoir release to preserve hydropower capacity. During flushing operations, discharge varied approximately from $10 \mathrm{~m}^{3} / \mathrm{s}$ to $150 \mathrm{~m}^{3} / \mathrm{s}$ and water color was very turbid due to very high concentrations of fine suspended sediments (between 10 and $30 \mathrm{~g} / \mathrm{l}$ ). Two distinct study sites were selected on the same ap- 


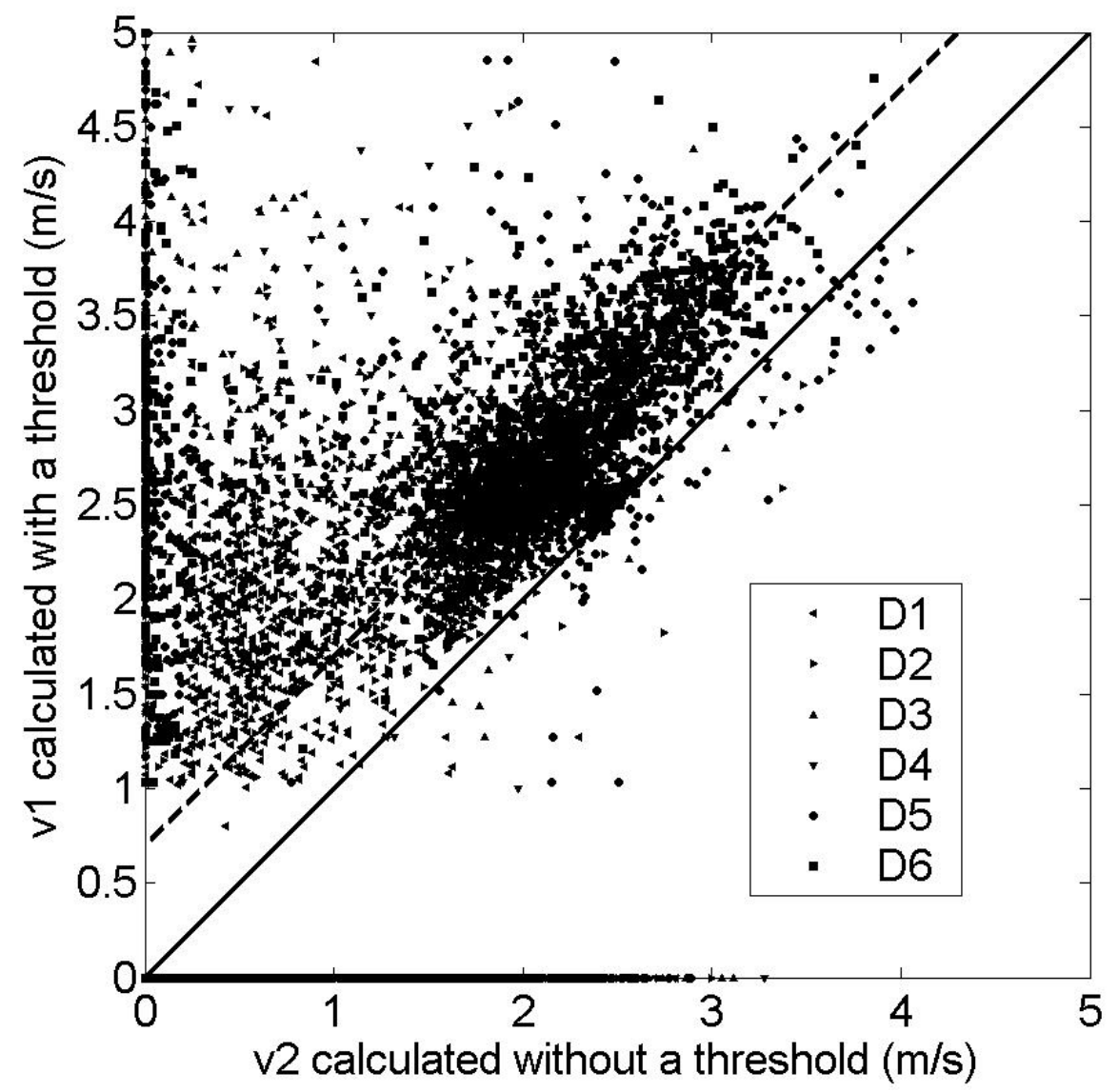

Figure 3: Comparison of calculated velocities with (v1) or without (v2) the use of a threshold level on gray scale images to detect tracers only. Line represents equality between v1 and v2, and dashed line stands for a $0.7 \mathrm{~m} / \mathrm{s}$ interval. 
proximately $50 \mathrm{~m}$ large river reach. The flow was recorded from the $5 \mathrm{~m}$ high embankment, the mast height was set to $8.4 \mathrm{~m}$, surveyed areas were approximately $60 \mathrm{~m} \times 40 \mathrm{~m}$. Thus the tilt angle of the camera axis was thus about 20 degrees (angle between horizontal direction and direction from the camera to the field of view center).

The first view-point (SITE D) was chosen just downstream a gravel bar where the flow was quite simple. It permits assessments of flow velocity over the whole width of the river. Results are named D1 to D6.

The second view-point (SITE C) allowed monitoring the complex flow patterns produced by an upstream permanent connecting channel on the same gravel bar. Results are named $\mathrm{C} 1$ and $\mathrm{C} 2$.

Additional measurements were performed during the flushing event: water level was measured at four points using bubble pipe devices (ISCO 4230, one measurement per minute), two discharge measurements with leaded current meter were performed at a bridge $200 \mathrm{~m}$ downstream. Low flow discharge was regularly monitored over the year using wadable currentmeter measurements. the bathymetry of the river reach was surveyed before and after the flushing event with a GPS system (Trimble 5800 RTK).

\subsection{Relationship between surface velocity and depth-averaged ve- locity}

In order to compare LS-PIV measurements with conventional measurements or with depthaveraged numerical results, the relationship between surface velocity and depth-averaged velocity must be established. As considered in many previous studies [26, 27, 28, 29], ver- 
Author-produced version of the article published Flow Measurement and Instrumentation (2008), 19, 2, 117-127,

The original publication is available at http://www.sciencedirect.com DOI: 10.1016/j.flowmeasinst.2007.11.004

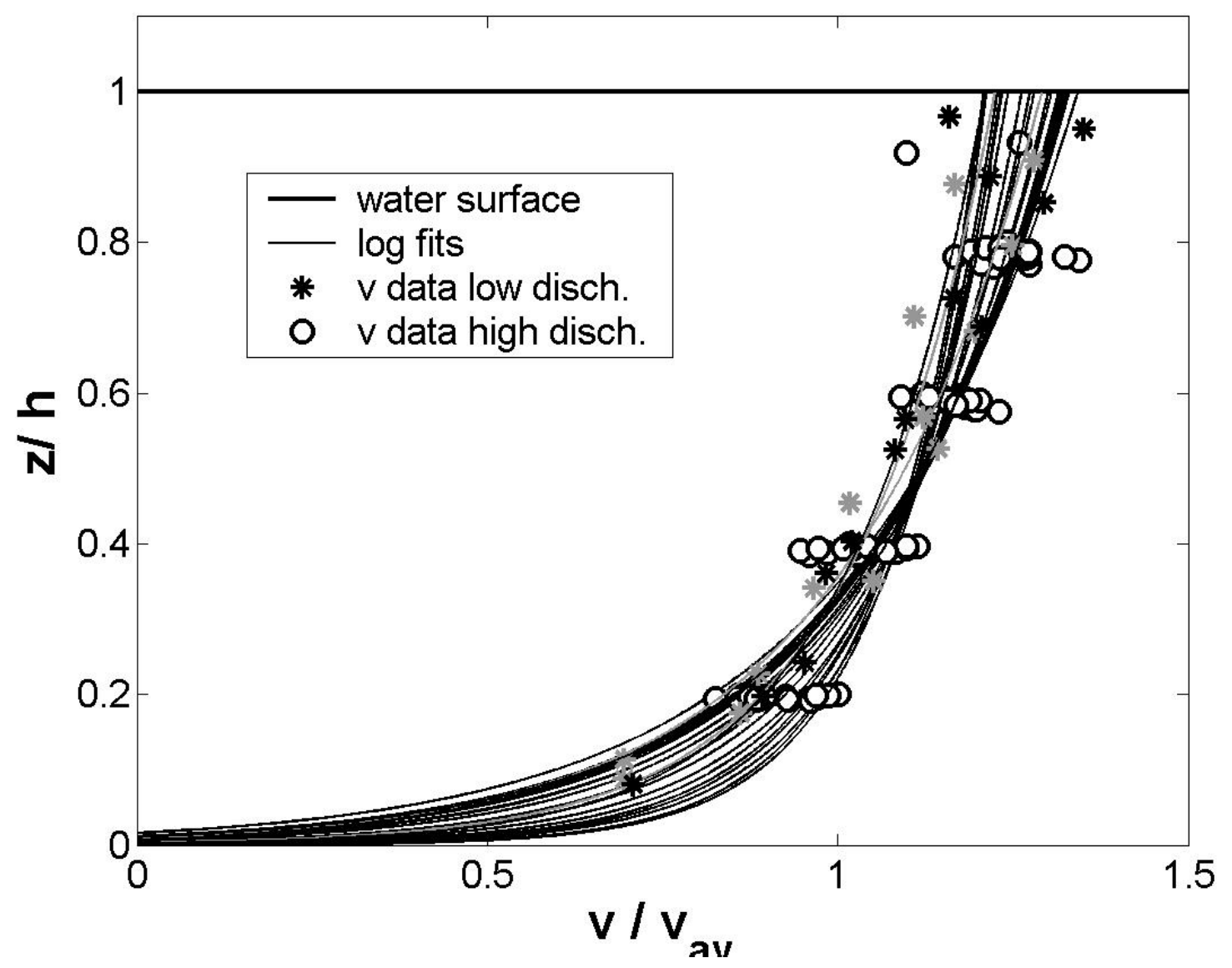

Figure 4: 24 dimensionless vertical velocity profiles fitted on 24 velocity data sets measured at high discharge $\left(102 \mathrm{~m}^{3} / \mathrm{s}\right.$ and $\left.115 \mathrm{~m}^{3} / \mathrm{s}\right)$ and at low flow $\left(5.5,16\right.$ and $\left.20 \mathrm{~m}^{3} / \mathrm{s}\right)$. 
tical velocity profiles are assumed to follow a logarithmic law : $v(z)=A \ln \left(\frac{z}{z_{0}}\right)$, where A is a coefficient, $z$ the elevation above the bed and $z_{0}$ the elevation at which velocity is zero, depending on the bed roughness. This vertical generic law was confirmed by velocity measurements performed at the bridge at high discharge $\left(102 \mathrm{~m}^{3} / \mathrm{s}\right.$ and $\left.115 \mathrm{~m}^{3} / \mathrm{s}\right)$ and detailed vertical velocity profiles performed at low flow $\left(5.5,16\right.$ and $\left.20 \mathrm{~m}^{3} / \mathrm{s}\right)$. Dimensionless data fit reasonably with dimensionless logarithmic velocity profiles whatever the intensity of the discharge is (Figure 4). The bed roughness parameter $z_{0}$ can be deduced from fitted $\log$ law, leading to $z_{0}$ values from $0.001 \mathrm{~m}$ to $0.015 \mathrm{~m}$, which is coherent with observed surface grain-sizes of several centimeters. The float coefficient $\alpha_{v}=v_{a v} / v_{\text {surface }}$ can be deduced from the dimensionless logarithmic law: $w(z / h=1)=v(z=h) / v_{a v}=1 / \alpha_{v}$. This simple relationship between surface and depth-averaged velocities $\left(\alpha_{v} \approx 1-1 / \ln \left(h / z_{0}\right) \approx\right.$ constant $)$ is valid only for $h>100 z_{0}$, which is equivalent to approximately $40 \mathrm{~cm}$. Data presented here lead to $\alpha_{v}$ from 0.75 to 0.83 , for this data set the condition $h>100 z_{0}$ is always fulfilled. In the following calculations, the mean value of all the experimental values, $\alpha_{v}=0.79$, will be used to convert surface velocity into depth-averaged velocity. This value is smaller than the usual 0.85 coefficient used for instance by $[26,10]$.

\subsection{Comparison with $2 \mathrm{Dh}$ calculations}

The depth-averaged (2Dh) water flow in the reach was modeled with the two-dimensional model Rubar20. The code Rubar20 uses a finite volume scheme that is explicit, Godunovtype and second order accurate [30]. It solves the 2-dimensional shallow water equations written below : 


$$
\begin{aligned}
& \frac{\partial h}{\partial t}+\frac{\partial h u}{\partial x}+\frac{\partial h v}{\partial y}=0 \\
& \frac{\partial h u}{\partial t}+\frac{\partial\left(h u^{2}+g h^{2} / 2\right)}{\partial x}+\frac{\partial h u v}{\partial y}=-g h \frac{\partial Z}{\partial x}-g n_{M}^{2} \frac{u \sqrt{u^{2}+v^{2}}}{h^{1 / 3}}+K\left[\frac{\partial}{\partial x}\left(h \frac{\partial u}{\partial x}\right)+\frac{\partial}{\partial y}\left(h \frac{\partial u}{\partial y}\right)\right] \\
& \frac{\partial h v}{\partial t}+\frac{\partial h u v}{\partial x}+\frac{\partial\left(h v^{2}+g h^{2} / 2\right)}{\partial y}=-g h \frac{\partial Z}{\partial y}-g n_{M}^{2} \frac{v \sqrt{u^{2}+v^{2}}}{h^{1 / 3}}+K\left[\frac{\partial}{\partial x}\left(h \frac{\partial v}{\partial x}\right)+\frac{\partial}{\partial y}\left(h \frac{\partial v}{\partial y}\right)\right]
\end{aligned}
$$

in which $u$ and $v$ are depth-averaged velocities along respectively $x$ and $y$ axis, $h$ water depth, $Z$ bottom level, $g$ gravity acceleration, $n_{M}$ Manning coefficient, $K$ the viscosity coefficient. The mesh is constituted of quadrangles or triangles which have 0 or 1 common edge, it includes the whole gravel bar (Figure 5). Bed topographies before and after the event were meshed. In order to obtain the mean water level along the reach of interest, the Manning friction coefficient $n_{M}$ is taken constant over the whole reach $\left(n_{M}=0.025 \mathrm{~m}^{-1 / 3} \mathrm{~s}\right)$, excepted on boulder embankments $\left(n_{M}=0.05 \mathrm{~m}^{-1 / 3} \mathrm{~s}\right)$ to reproduce higher friction due to large boulders and sparse vegetation and at the bar tail (downstream part) $\left(n_{M}=0.017 \mathrm{~m}^{-1 / 3} \mathrm{~s}\right)$ to account for finer gravels. At the upstream cross-section, we used a hydrograph and water level measurements as boundary conditions. The hydrograph is the discharge time series presented in 4.1 (Figure 8). At the downstream cross-section the water level is set to critical regime.

Difficulties to fit the simulated water level line to measurements were encountered mainly because water level lines from calculation are significantly influenced by the topography used to build the mesh. This numerical approach does not take into account gravel bed changes. Our topography measurements show obvious changes of the bed during the flushing event. Knowing this, it is quite difficult to choose which topography corresponds to a given period of time. 


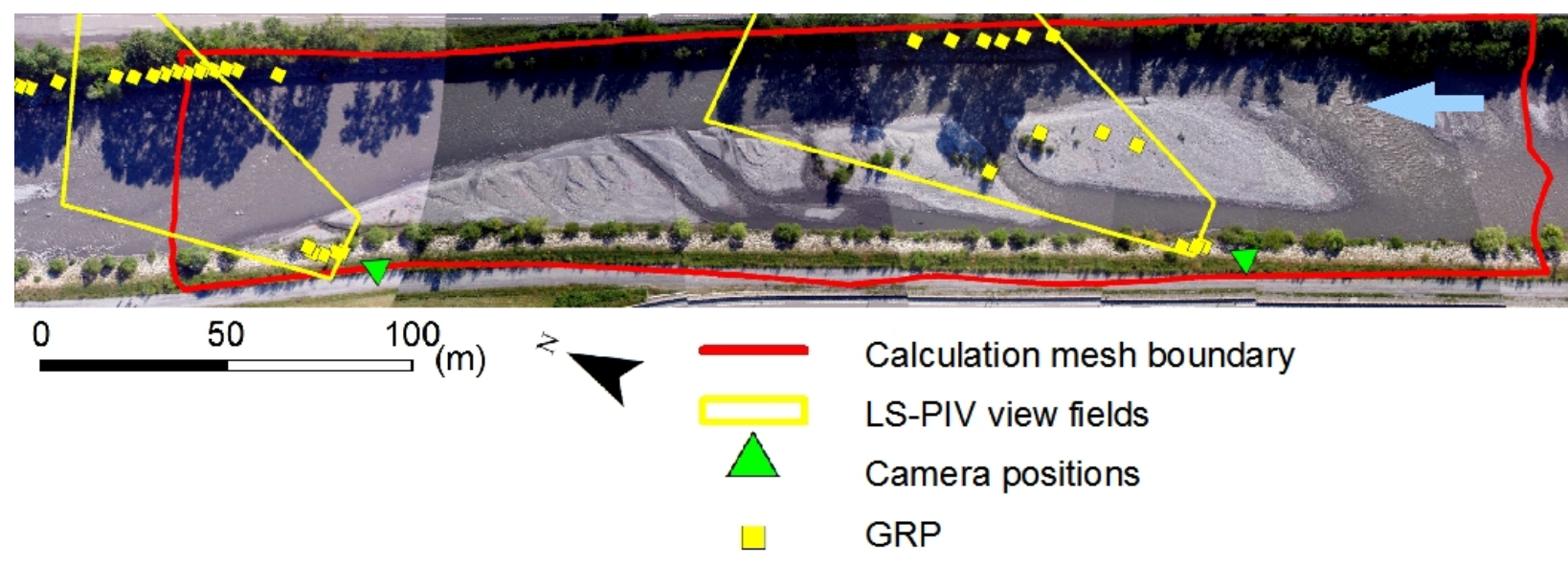

Flow direction

Figure 5: LS-PIV installation with the positions of the camera and the view fields, the GRPs and the boundary of the calculation mesh.

Figure 6 shows comparison between LS-PIV measurements and velocities calculated by the model. As the LS-PIV calculation grid is finer than the numerical model mesh, each of the numerical calculations is compared to the nearest LS-PIV assessment. Two conditions are applied to preserve the relevance of the comparison: (i) the compared data must be located nearer than one meter and (ii) the angle between both velocity vectors must be lower than $\pi / 5$, otherwise it probably means that LS-PIV measurement is biased, for instance due to spurious movements. The float coefficient $\alpha_{v}=0.79$ was used to compare LS-PIV surface velocities to depth-averaged calculated velocities (see 4.2).

In both sites, angles between numerically calculated velocities and field measurements are similar. Only a few locations (on the edge of the areas of interest) show differences higher than $\pm \pi / 10$. As the flow patterns on SiTE D are more simple the difference between both 

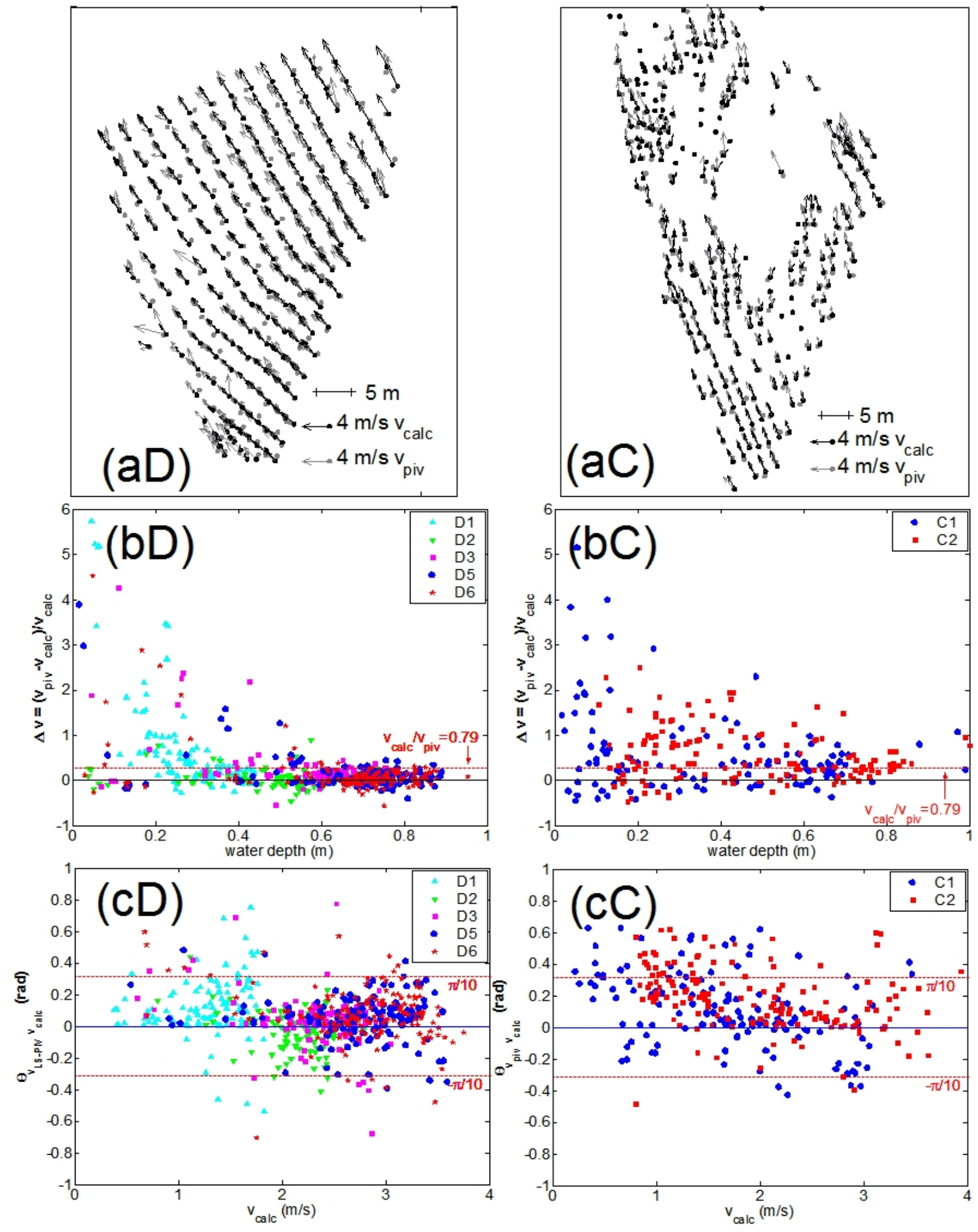

Figure 6: Comparison between LS-PIV velocity measurements $\left(\mathrm{v}_{\text {piv }}\right)$ and 2Dh numerical calcu19

lations $\left(\mathrm{v}_{\text {calc }}\right.$ ) on Site D and Site C: (a) velocity fields, (b) intensity comparison, (c) direction comparison. 
vectors is mainly less than $\pm \pi / 40 \approx 5^{\circ}$.

On SiTE D, accordance between calculated and measured velocity intensities is excellent for water depths higher than $50 \mathrm{~cm}$ (Figure $6 \mathrm{bD}$ ). Discrepancy is observed for low water-depths corresponding to the near field, ie the part of the flow near the left embankment. Visual controls on movies confirm the value of the velocities in the near field, in this area tracers move approximately at the same velocity as tracers in the middle of the river. As the bias seems to depend on the water depth, the underestimation may be linked to inaccurate calculations at low water depths due an erroneous statement of friction. The bias is strongly noticeable for sequence D1 (lowest discharge) in which water-depths are lower than $50 \mathrm{~cm}$ in the whole cross-section. As this sequence was monitored at the beginning of the flushing event when discharge varied quickly, a small error in time in the calculated discharge time series could generate a considerable discrepancy between real discharge and estimated discharge. D1 measurements are in better agreement with calculations performed ten minutes later.

On Site C, where the flow is more complex, LS-PIV velocities differ from calculated velocities for a great part (Figure $6 \mathrm{bC}$ ). Agreement between both velocities is acceptable in the near field upstream from the connecting channel.

For further comparisons, calculated velocity vectors were interpolated on the cross sections mapped on Figure 2 and LS-PIV surface velocities were multiplied by the float coefficient $\alpha_{v}=0.79$. On Site D, Figure 7 (a) and (b) shows that calculations fit fairly well with measurements except in a limited area near the left embankment, as observed in previous comparisons. In this latter area, calculations underestimate velocity intensities (Figure 7 b). The asymmetry of transverse velocity profile is obvious on calculation results whereas measurements show an almost symmetric transverse profile. Lack of data close to the right 

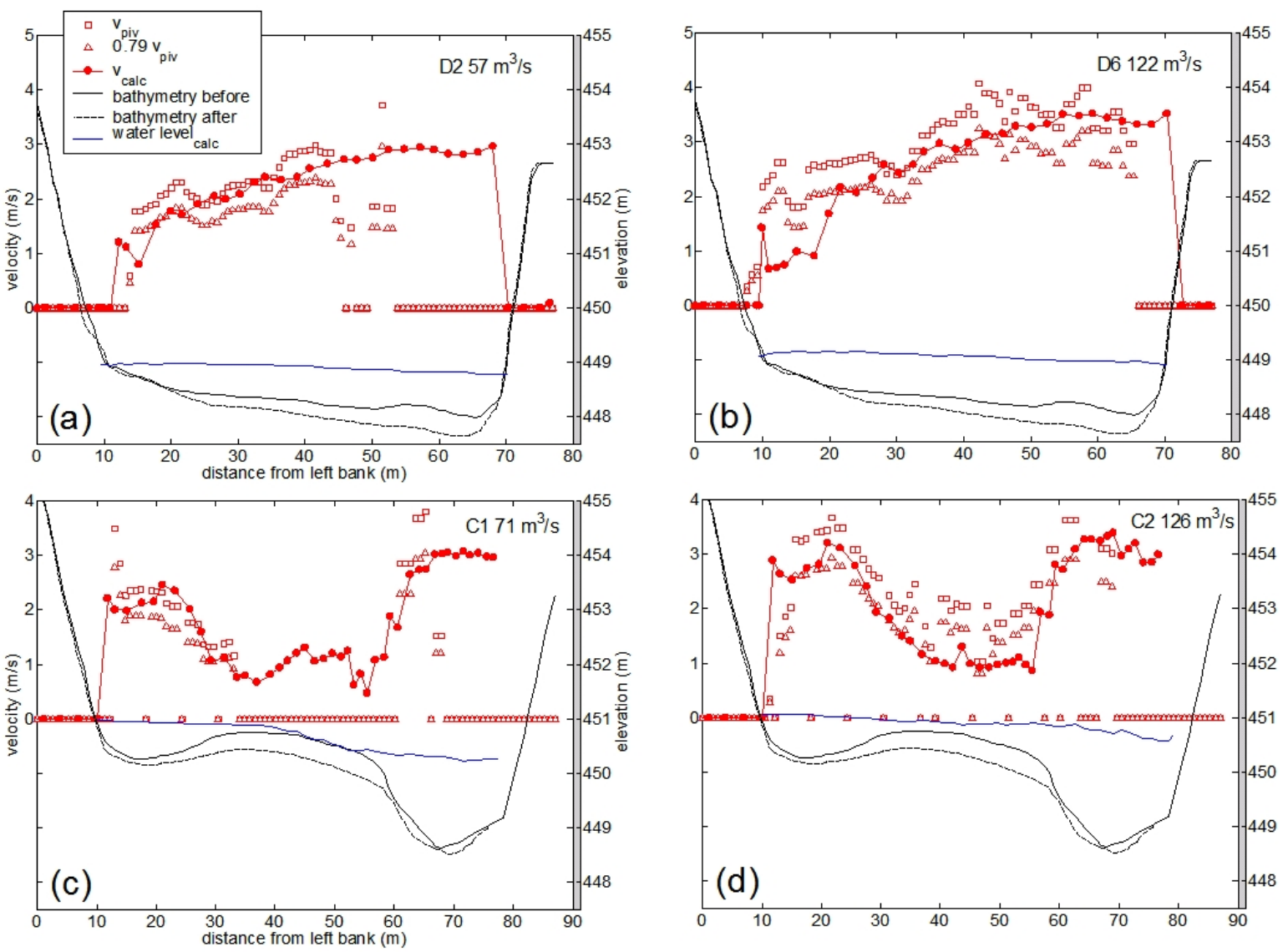

Figure 7: Comparison on cross-section between LS-PIV velocity measurements $\left(\mathrm{v}_{\text {piv }}\right)$ and $2 \mathrm{Dh}$ numerical calculations $\left(\mathrm{v}_{\text {calc }}\right)$. On SITE D (a) D2, in the beginning of the flushing event, $\mathrm{Q}=57 \mathrm{~m}^{3} / \mathrm{s}$, and (b) D6 at the peak discharge, $Q=122 \mathrm{~m}^{3} / \mathrm{s}$. On Site $\mathrm{C}$ (c) $\mathrm{C} 1$, in the rising phase, $\mathrm{Q}=71 \mathrm{~m}^{3} / \mathrm{s}$ and $(\mathrm{d}) \mathrm{C} 2$ at the peak discharge, $\mathrm{Q}=126 \mathrm{~m}^{3} / \mathrm{s}$. 
embankment occurred in some of the sequences due to tree shadows and absence of tracers. Considering previous cross-section profiles, it is acceptable to consider constant interpolation in this region. Thus the model validates LS-PIV velocity assessments and could be a way to face lack of field measurement in space and time.

On Site C, Figures 7 (c) and (d) show that the available measurements agree with the calculations. Despite very few measurements in the main channel, the global shape of the transverse profile is similar in both cases.

\subsection{Discharge calculations}

Using low water wading current-meter discharge measurement and both high flow currentmeter discharge measurements at the bridge, an exponential rating curve was built associated with continuous water level monitoring near SITE D. As the depth data quickly fluctuate, a 3 minute moving average was used to smooth the water depth signal. The resulting reference discharge time series $(\mathrm{REF})$ is plotted on Figure 8, fluctuations are within the associated \pm 5 $\%$ curves.

Local discharge estimates over the whole flushing event were performed using LS-PIV velocity measurements. Calculation is performed on a simple quasi-transverse oblique stream section downstream to the gravel bar at site D (Figure 2 (b)). Topography of the gravel bed evolved during the flushing event. As only two bed surface DEMs (Digital Elevation Models) are available, the first one standing for topography before the flushing event is used till peak discharge is reached, whereas the second one standing for the topography after the event is used as reference for the second part of the flushing event. Surface velocity values are converted into depth-averaged velocities using a coefficient $\alpha_{v}=0.79$ (4.2). DEM and depthaveraged projected velocities are computed using inverse distance weighting interpolation 


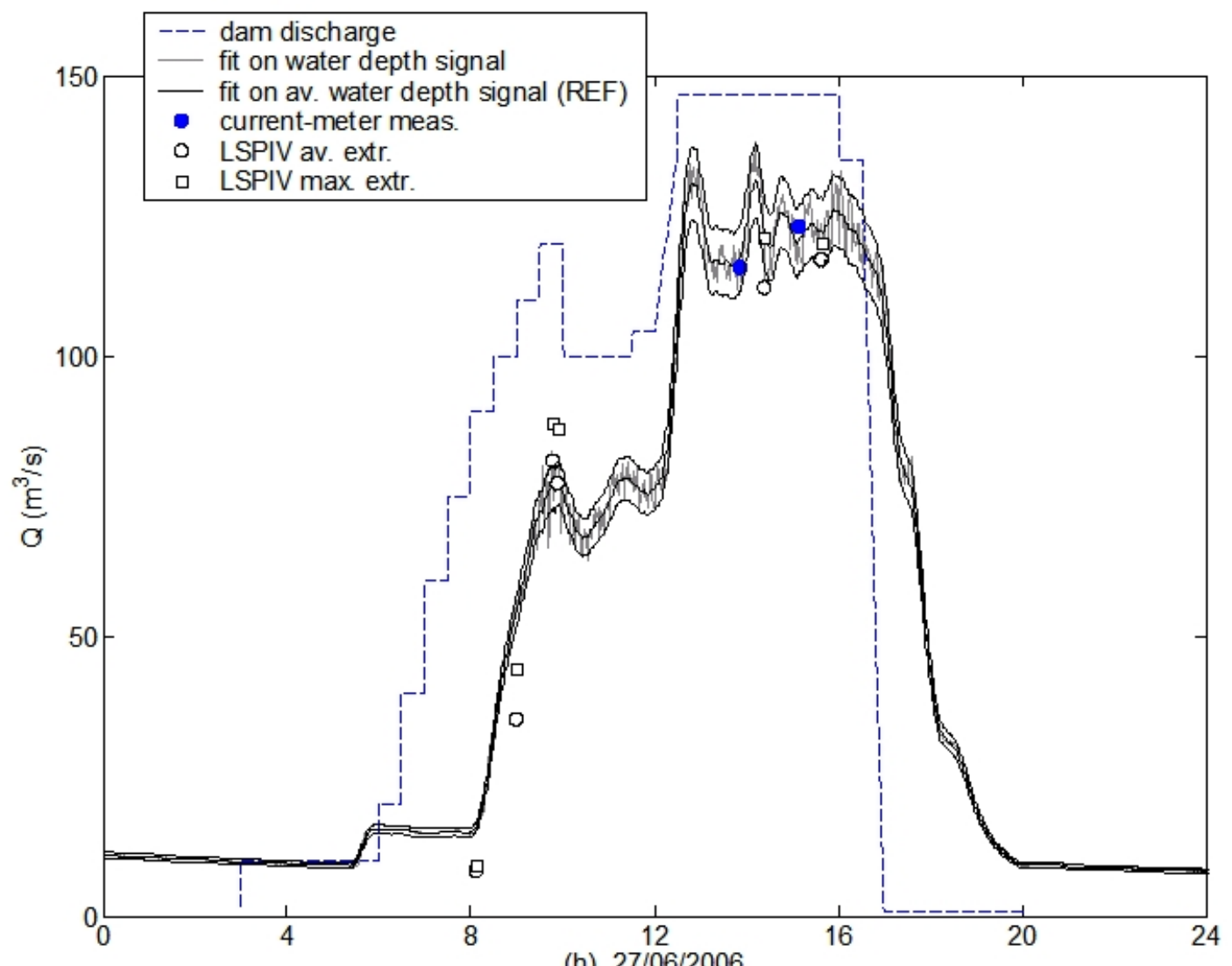

Figure 8: Discharges from different calculations: assessment from dam managers using incoming discharges and measured water level near the gates; estimates based on water depth signal or timeaveraged water depth signal at the study site using a rating curve; current-meter measurements from the $200 \mathrm{~m}$ downstream bridge; LS-PIV calculations using extrapolation with constant value (width-averaged or maximum value). 
to $n_{t}=100$ equally spaced points on the section $(\Delta l=0.77 \mathrm{~m}$ between two calculation points). A mean longitudinal bed slope of $0.3 \%$ deduced from DEMs is applied to extrapolate flow depths from measurements. In case of an absence of measurement due to shadows or absence of tracers on the right side of the stream, extrapolation of surface velocities with constant value, $v_{\text {extr }}$ is performed. The number of extrapolated data related to the number of calculation points (100), $f_{\text {extr }}$, gives an estimate of the reliability of the discharge assessment. The extrapolated values were chosen to be constant, either the average of the measured values for $h \neq 0$ or the maximum of cross-section surface velocity values. This second value is coherent with the comparison between measured and numerically calculated velocities (4.3). Discharges are calculated using the following formula:

$$
Q=\sum_{i=1}^{n_{t}} v_{P i} h_{i} \Delta l=\underbrace{\Delta l \sum_{i=1}^{\left(1-f_{\text {extr }}\right) n_{t}} v_{P i} h_{i}}_{\text {measurements }}+\underbrace{\Delta l v_{\text {extr }} \sum_{i=\left(1-f_{\text {extr }}\right) n_{t}}^{n_{t}} h_{i}}_{\text {extrapolation }}
$$

where $v_{P i}$ is the interpolated depth-averaged projected velocity, normal velocity vector to the cross-section, and $h_{i}$ is the interpolated water-depth at point $\mathrm{i}$ on the cross section, and $\Delta l$ is the distance between two calculation points, $n_{t}$ is the number of calculation points. Discharge assessments from these calculations are reported in Table 1. Discharge calculations based on LS-PIV assessments without threshold processing are not presented here but give discharge estimates $70 \%$ lower than those presented here. It confirms the need to clearly focus on moving surface patterns.

The measurements performed from the downstream bridge give discharge peak values significantly lower than those estimated by dam managers $\left(120 \mathrm{~m}^{3} / \mathrm{s}\right.$ versus $\left.150 \mathrm{~m}^{3} / \mathrm{s}\right)$. There is no loss of water between the downstream dam and the study site and one dimensional modeling of the flushing event from the dam to the study site showed no decreasing of the peak value along the river. Even though the uncertainty of discharge measurements with 


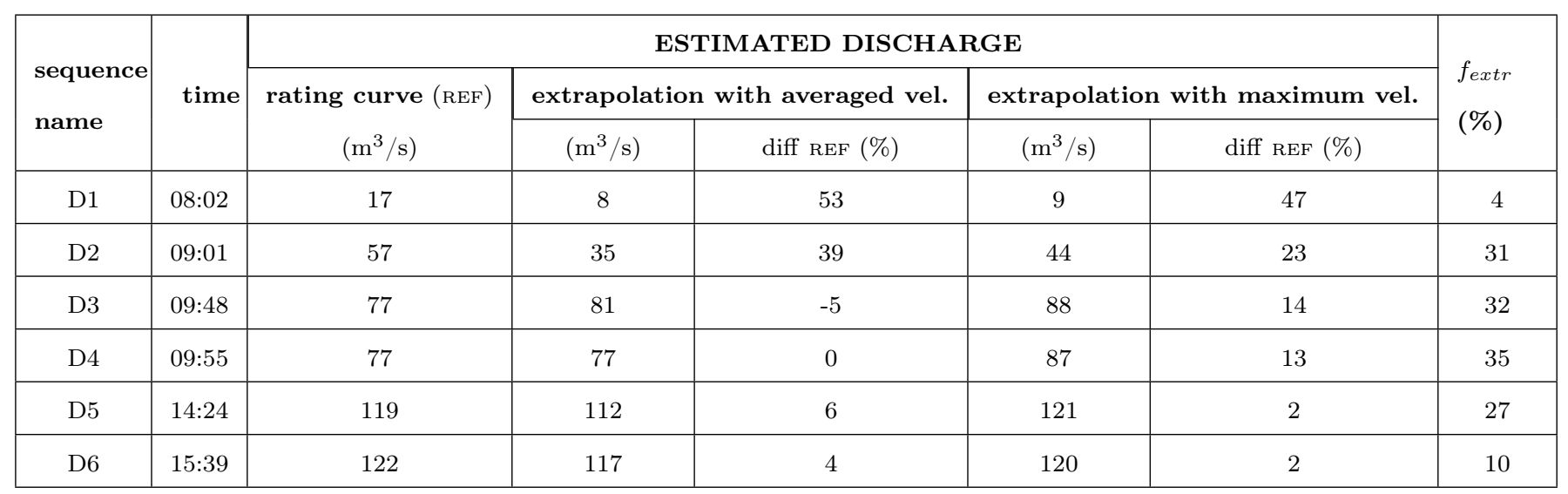

Table 1: Comparison between discharges estimated with the rating curve and discharges calculated with LS-PIV estimates according two methods: extrapolation with width-averaged velocity or extrapolation with maximum velocity.

leaded current-meter can be estimated to be $\pm 5 \%$ of the true value [31], this measurement is more reliable than rating-based discharge assessment. Consequently measurements performed with the current meter at the bridge were considered as references for peak discharge values rather than the assessments at the upstream dam.

LS-PIV measurements are compared with the discharge time series built independently as described in 4.1.The resulting discharge time series is plotted on Figure 8, which shows that the shape of the assessed hydrograph proposed by dam managers is similar to the one calculated here whereas peak discharge seems to be overestimated by dam managers.

LS-PIV discharge estimations fit well with both discharge measurements from the bridge and the new computed discharge curve and consequently validate the calculations. Checking assessed data is a major issue to further use of the hydrograph, for instance in numerical modeling of the event or in analysis of morphological changes of the river bed. 


\section{Conclusion and perspectives}

During high flow conditions, LS-PIV technique can be used to measure flow surface velocities. A complete installation including a video acquisition system from a mobile elevated viewpoint and an artificial feeding device similar was used to record large images of a river flow surface during a reservoir release.

Improvement of LS-PIV method has been developed to obtain velocity assessments despite water surface elevation variations, stationary waves and light reflections. The improved LSPIV method is evaluated for velocity measurements in a moutain stream during a high flow event.

A float coefficient $\alpha_{v}=0.79$ based on field measurements was used to convert surface velocities into depth-averaged velocities. Comparisons with 2Dh numerical calculations showed good agreement between measured and calculated velocities, thus it is a useful tool to verify and extrapolate LS-PIV data.

Discharge calculation from LS-PIV surface velocities were consistent with current-meter measurements, and validate the calculation of a new discharge time-series which is significantly different in intensity from dam manager assessments.

The installation and methods are now operational for further studies. The facility is not limited to artificial high flow events in rivers and could be applied to the study of natural unpredictable floods, for instance flash-floods occurring in Mediterranean regions, or the monitoring of flow patterns in reservoirs to increase the efficiency of reservoir flushing procedures. 
In case of an absence of natural tracers, the uniformity of the artificial tracers seeding could be improved by using several seeding containers or a more sophisticated device, maybe a permanent installation using a wire line instead of a rope would facilitate the seeding. Our results were also affected by shadow limitations, but some improvement on data processing could probably enhance the quality of the results.

\section{Acknowledgments}

This study was supported by the Cemagref. Diren Rhône-Alpes performed discharge measurements at the downstream bridge. EDF Groupe d'Exploitation Hydraulique Maurienne provided discharge assessments and authorized measurements during the reservoir release. Authors are grateful to people who took part in the field survey, in particular F. Thollet and J. Hervé. 


\section{Annex 1}

Coefficients $m_{i}, p_{i}$ and $q_{i}$ for the inverse relation mapping image coordinates onto Cartesian coordinates read as follows:

$$
\begin{aligned}
& m_{1}=d_{3}\left(b_{2} c_{3}-b_{3} c_{2}\right)+\left(b_{2}-b_{4} c_{2}\right) \\
& m_{2}=-\left\{d_{3}\left(a_{2} c_{3}-a_{3} c_{2}\right)+\left(a_{2}-a_{4} c_{2}\right)\right\} \\
& m_{3}=d_{3}\left(a_{2} b_{3}-a_{3} b_{2}\right)+\left(a_{2} b_{4}-a_{4} b_{2}\right) \\
& p_{1}=\left(b_{1} c_{2}-b_{2} c_{1}\right) \\
& p_{2}=-\left(a_{1} c_{2}-a_{2} c_{1}\right) \\
& p_{3}=\left(a_{1} b_{2}-a_{2} b_{1}\right) \\
& q_{1}=-\left\{d_{3}\left(b_{1} c_{3}-b_{3} c_{1}\right)+\left(b_{1}-b_{4} c_{1}\right)\right\} \\
& q_{2}=d_{3}\left(a_{1} c_{3}-a_{3} c_{1}\right)+\left(a_{1}-a_{4} c_{1}\right) \\
& q_{3}=-\left\{d_{3}\left(a_{1} b_{3}-a_{3} b_{1}\right)+\left(a_{1} b_{4}-a_{4} b_{1}\right)\right\}
\end{aligned}
$$

\section{References}

[1] A. Sukhodolov, W.S.J. Uijttewaal, and C. Engelhart. On the correspondance between morphological and hydrodynamical patterns of groyne fields. Earth Surface Processes and Landforms, 27:289-305, 2002.

[2] P.J. Ashworth. Mid-channel bar growth and its relationship to local flow strength and direction. Earth Surface Processes and Landforms, 21:103-123, 1996.

[3] P. Whiting and W. Dietrich. Experimental studies of bed topography and flow patterns 
in large-amplitude meanders 1. Observations. Water Resources Research, 29:3605-3614, 1993.

[4] B.C. Eaton and M.F. Lapointe. Effects of large floods on sediment transport and reach morphology in the cobble-bed Sainte Marguerite River. Geomorphology, 40:291-309, 2001.

[5] J.-Y. Lu, C.-C. Su, and C.-Y. Wang. Application of a portable measuring system with acoustic Doppler current profiler to discharge observations in steep rivers. Flow Measurement and Instrumentation, 17:179-192, 2006.

[6] I. Fujita, M. Muste, and A. Kruger. Large-scale particle image velocimetry for flow analysis in hydraulic engineering applications. Journal of Hydraulic Research, 36:397414, 1998.

[7] V. Weitbrecht, G. Kühn, and G.H. Jirka. Large scale PIV-measurements at the surface of shallow water flows. Flow Measurement and Instrumentation, 13:237-245, 2002.

[8] D.M. Admiraal, J.S. Stansbury, and C.J. Haberman. Case study: Particle velocimetry in a model of lake Ogallala. Journal of Hydraulic Engineering, 130:599-607, 2004.

[9] S.A. Kantoush, J.-L. Bollaert, E.F.R.and Boillat, and W.S.J. Schleiss, A.J.and Uijttewaal. Experimental study of suspended sediment transport and deposition in a rectangular shallow reservoir. In Ferreira, Alves, Leal, and Cardoso, editors, River Flow 2006, pages $1623-1630,2006$.

[10] J.D. Creutin, M. Muste, A.A. Bradley, S.C. Kim, and A. Kruger. River gauging using PIV techniques: a proof of concept experiment on the Iowa river. Journal of Hydrology, 277:182-194, 2003. 
[11] A. Hauet, J.D. Creutin, P. Belleudy, M. Muste, and W. Krajewski. Discharge measurements using Large Scale PIV under varied flow conditions, recent results, accuracy and perspectives. In Ferreira, Alves, Leal, and Cardoso, editors, River Flow 2006, pages 1829-1833, 2006.

[12] A. Hauet, A. Kruger, W. Krajewski, A. Bradley, M. Muste, J.D. Creutin, and M. Wilson. Experimental system for real-time discharge estimation using an image-based method. Journal of Hydrologic Engineering, February 2008.

[13] J.C. Smith, F. Bérubé, and N.E. Bergeron. A field application of particle image velocimetry (PIV) for the measurement of surface flow velocities in aquatic habitat studies. In Paper No. 87, Proceedings of the 26th Canadian Symposium on Remote Sensing, Wolfville, Nova Scotia, June 14-16, 2005, 2005.

[14] I. Fujita and T. Nakashima. Image-based technique for river monitoring. In 1999 IAHR Congress Proceedings Graz, page 425, 1999.

[15] M. Jasek, M. Muste, and R. Ettema. Estimation of Yukon River discharge during an ice jam near Dawson City. Can. J. Civ. Eng., 28:856-864, 2001.

[16] I. Fujita and T. Hino. Unseeded and seeded PIV measurements of river flows videotaped from a helicopter. Journal of Visualization, 6:245-252, 2003.

[17] Y. Muto, Y. Baba, and S. Aya. Velocity measurements in open channel flow with rectangular embayments formed by spur dikes. Annuals of Disaster Prevention Research Institute, Kyoto University, 45B:2, 2002.

[18] M. Jodeau, A. Paquier, A. Hauet, J. Le Coz, F. Thollet, and T. Fournier. Effect of a 
reservoir release on the morphology of a gravel bar: field observations and $2 \mathrm{dh}$ modeling. In RCEM2007, 2007.

[19] Alexandre Hauet. Estimation de débit et mesure de vitesse en rivière par LargeScale Particle Image Velocimetry, Discharge estimates and velocity measurements using Large-Scale Particle Image Velocimetry (in French). PhD thesis, INP Grenoble, France, 2006.

[20] I. Fujita, M. Hara, Morimoto, T., and T. Nakashima. Visualization and PIV measurement of river surface flow. In Proceeding of VSJ-SPIE98, 1998.

[21] A. M. Fincham and G.R. Spedding. Low cost, high resolution DPIV for measurement of turbulent fluid flow. Experiments in Fluids, 23:449-462, 1997.

[22] D. J. Forliti, P. J. Strykowski, and K. Debatin. Bias and precision errors of digital particle image velocimetry. Experiments in Fluids, 28:436-447, 2000.

[23] J. Le Coz, H. Hauet, F. Védie, G. Dramais, B. Chastan, and A. Paquier. Recirculating flow assessment from aDcp, LS-PIV and 2Dh modelling. In Ferreira, Alves, Leal, and Cardoso, editors, River Flow 2006, 1843-1851, 2006.

[24] E.A. Meselhe, T. Peeva, and M. Muste. Large scale image velocimetry for low velocity and shallow water flows. Journal of Hydraulic Engineering, 130:937-940, 2004.

[25] I. Fujita and S. Aya. Refinement of LSPIV technique for monitoring river surface flows. In $A S C E$ conference proceedings, 2004.

[26] S.E. Rantz. Measurement and computation of streamflow: Volume 2. Computation of discharge. Technical report, USGS, 1982. 
[27] P.R. Wilcock, G.M. Kondolf, W.V.G. Matthews, and A.F. Barta. Specification of sediment maintenance flows for a large gravel-bed river. Water Resources Research, 32:29112921, 1996.

[28] G. M. Smart. Turbulent velocity profiles and boundary shear stress in gravel bed rivers. Journal of Hydraulic Engineering, 125:106-116, 1999.

[29] JE. Costa, RT. Cheng, FP. Haeni, N. Melcher, KR Spicer, E. Hayes, W. Plant, K. Hayes, C. Teague, and D. Barrick. Use of radar to monitor stream discharge by noncontact methods. Water Resources Research, 42:1-14, 2006.

[30] A. Paquier. Modélisation et simulation de la propagation de l'onde de rupture de barrage (in French). PhD thesis, Université Jean Monnet, St Etienne, France, 1995.

[31] V. B. Sauer and R. W. Meyer. Determination of error in individual discharge measurements, open file report 92-144. Technical report, USGS, 1992. 